\title{
A LITERATURA DO SÉCULO XIX E RELATO DE UM CERTO ORIENTE, DE MILTON HATOUM
}

\section{MARIANA MAURÍCIO*}

Universidade de Lisboa (ULisboa), Programa de Pós-Graduação em Estudos Portugueses e Românicos, Lisboa, Portugal.

Recebido em: 18 fev. 2020. Aprovado em: 2 mar. 2021.

Como citar este artigo: MAURÍCIO, M. A literatura do século XIX e Relato de um certo Oriente, de Milton Hatoum. Cadernos de Pós-Graduação em Letras, v. 21, n. 11, p. 197-211, jan./abr. 2021. doi: 10.5935/ cadernosletras.v21n1p197-211

\section{Resumo}

Adotando como ponto de partida a vontade manifestada por Milton Hatoum de evitar, no seu livro Relato de um certo Oriente, a tradição regionalista associada ao romance amazónico, o presente artigo visa estabelecer relações intertextuais entre aquele romance e vários textos canónicos da literatura naturalista e realista do século XIX. Nomeadamente, estabelecem-se relações com o drama burguês e com diversas personagens das peças de Henrik Ibsen, e procura-se explorar a proximidade entre o romance de Hatoum e algumas referências da obra de Flaubert e Machado de Assis.

* E-mail: marianafariamauricio@gmail.com

(D) https://orcid.org/0000-0001-9001-7794 


\section{Palavras-chave}

Hatoum. Drama burguês. Flaubert.

\section{MILTON HATOUM PERANTE A TRADIÇÃO REGIONALISTA}

Quando um país deixa de estar submetido ao poder político de outro, a atividade literária pode fazer "parte do esforço de construção" de um "país livre” (CANDIDO, 1964, v. I, p. 28). No seguimento da independência do Brasil, a primeira missão assumida pelos escritores brasileiros românticos (como Franklyn Távora, Bernardo Guimarães, Taunay) foi a formação de uma literatura nacional. Fizeram-no escrevendo "sobre coisas locais" (CANDIDO, 1964, v. II, p. 112); ou seja, adotando a "paisagem como estímulo e expressão do nacionalismo" (CANDIDO, 1964, v. I, p. 217). A “cor local” e, pelas mesmas razões, a cultura indígena foram utilizadas na literatura como meios de afirmação da nacionalidade. Com a particularidade de, sob a influência do Romantismo, os autores brasileiros pós-independência aplicarem elementos românticos à cultura indígena (PELLEGRINI, 2004, p. 126). É o que acontece em obras como O guarani (1857), de José de Alencar, em que a influência das tradições medievais é substituída pela das tradições indígenas e o herói indígena assume o típico papel do cavaleiro andante. Com o fim do Romantismo, a missão nacionalista que impulsionou os escritores românticos desapareceu, mas o regionalismo perdurou em alguma literatura brasileira, continuando a denotar-se em obras literárias integradas em outras correntes estéticas. Desde logo, está presente no romance regionalista nordestino dos anos $1930,{ }^{1}$ o qual se conjuga com preocupações sociais. Atualmente, o regionalismo continua visível numa certa ficção, nomeadamente naquela em que o elemento paisagem é mais vivo e vincado, como é o caso da que adopta a Amazónia² como cenário.

1 Como Cacau (1933) e Suor (1936), de Jorge Amado.

2 É o caso do romance Lealdade (2001), de Márcio Souza, que aborda a formação histórico-política da Amazónia, mas também de Galvez - o imperador do Acre, de 1976, obra que marca o início da sua carreira literária. Tânia Pellegrini (2004) elenca algumas obras da literatura regionalista amazónica, com títulos evocativos do elemento indígena, como Pussanga (1929) e Matupá (1933), de Peregrino Júnior, Os igaraúnas (1938), de Raimundo de Morais, entre outros. 
Milton Hatoum é um escritor manauara. O seu romance Relato de um certo Oriente, publicado em 1989, passa-se em Manaus. Ao leitor pode razoavelmente ocorrer que está perante uma obra que se insere numa linhagem regionalista da ficção amazónica. No entanto, Hatoum tem procurado distanciar-se dessa estética. Ou mesmo contrariá-la, já que chegou a afirmar que uma obra literária deve fazer por quebrar a correspondência que se faz entre a literatura e a imagem que se tem de um país. A respeito do regionalismo, Milton Hatoum (apud BORGES, 2005) colocou a questão nos seguintes termos:

Antes de escrever o Relato, eu já estava vacinado contra a literatura regionalista. Não ia cair na armadilha de representar "os valores" e a cor local de uma região que, por si só, já emite traços fortes de exotismo. Percebi que podia abordar questões a partir da minha própria experiência e das leituras. E fiz isso sem censura, sem condescendência, usando recursos técnicos que aprendi com algumas obras.

Para alguns críticos, a vacina contra a literatura regionalista não foi totalmente eficaz. Tânia Pellegrini (2004, p. 125), por exemplo, num ensaio intitulado "Milton Hatoum e o regionalismo revisitado" defende que Relato se insere na ficção regionalista porque nele se reconhecem os "usos culinários, manejos linguísticos, crenças fundamentais que impregnam por igual os membros da comunidade [amazónica] e permitem que se reconheçam a si mesmos, diferenciando-se ou opondo-se a outros territórios”. Talvez tenha razão. No entanto, independentemente de essa fuga ao regionalismo ter sido ou não alcançada, dar crédito à intenção do autor significa também procurar identificar as leituras que lhe permitiram abordar questões relacionadas com a sua própria existência.

Algumas já foram identificadas pelo próprio Hatoum (2011), que atribui aos romances de Virginia Woolf a ideia de construir as personagens através de relatos de outras. Relato evoca, em primeira leitura, a tradição da literatura memorialista brasileira, de que são representantes, por exemplo, Dom Casmurro (1899), de Machado de Assis, e Grande sertão: veredas (1956), de João Guimarães Rosa (TEIXEIRO, 2013). E mais recentemente Lavoura arcaica de Raduan Nassar, que pode até ser entendido como "modelo literariamente iniciático para Hatoum” (TEIXEIRO, 2013, p. 71). Do ponto de vista da memória, a narração oral de tradição oriental é outra influência que se faz sentir, por exemplo, nos relatos do marido de Emilie sobre a chegada de Hakim à Ama- 
zónia, que o fotógrafo Dorner identifica como sendo transcrições adulteradas de contos das Mil e uma noites (TEIXEIRO, 2013). Essa influência da narração oral faz parte da herança de Hatoum, descendente de libaneses, que conta que na juventude em Manaus passava muito tempo na Pensão Fenícia, onde ouvia as histórias contadas pelos hóspedes do Médio Oriente.

Mas "ouvir dos mais velhos um conto das Mil e uma Noites ou uma passagem da vida do califa Harum ar-Rashid" era, segundo Hatoum (1993), "tão fascinante quanto ouvir de uma professora francesa um poema de Baudelaire ou contemplar, com um desejo exótico, um mapa de Paris". Ou seja, no que respeita à sua formação literária, Hatoum (que se tornou professor de literatura francesa) coloca a literatura francesa ao lado de influências tão presentes em Relato. Quanto a nós, nessa literatura de matriz francesa e europeia, que parece assentar a estrutura narrativa de Relato de um certo Oriente e que assim contribui também para a definição de vários tipos de personagens desse romance.

\section{O BRASIL E A CULTURA INDÍGENA EM RELATO DE UM CERTO ORIENTE}

Já se disse que “o Oriente feito por Hatoum são uma loja e uma casa em Manaus” (TOLEDO, 2006 apud TEIXEIRO, 2013, p. 72). É verdade que dentro da loja e da casa dessa família de origem árabe se sente pouco Brasil - no sentido regional, isto é, pouca Amazónia. De forma geral, essa presença apenas se sente quando o romance se abre ao exterior, quer quando a família sai desses dois espaços, quer quando deixa entrar no seu círculo de relações personagens ligadas à cultura indígena. Desde logo, quando a família central do romance prepara o dia das oferendas e a matriarca Emilie vai ao jardim do sobrado "pendurar nos galhos dos jambeiros as ampolas de vidro repletas de néctar de genipapo, para que os beija-flor ali bebericassem” (HATOUM, 1999, p. 130). Ou quando, observado por Dorner, o tio Emir faz o último passeio matinal antes do suicídio, o passeio que fazia sempre, desde a "travessia do igarapé" até "à praça Dom Pedro II, a rua dos grandes armazéns, a visão dos mastros, das quilhas e das altas chaminés” (HATOUM, 1999, p. 82). E é também quando a narradora faz o caminho de casa de sua mãe até ao sobrado da família e repara que 
[...] os leões de pedra, o javali e a Diana de Borzen permaneciam nos mesmos lugares da praça, entre as acácias e os bancos onde as pessoas sentadas ou deitadas contemplavam as telhas de vidro do coreto e os répteis rumando à beira do lago, atraídos pela sombra das garças e jaburus que dormiam ou fingiam dormir, equilibrados por hastes finíssimas que sumiam na água (HATOUM, 1999, p. 160).

Também vemos a cidade flutuante de Manaus, quando o pai da família central do romance para ali vai conversar com "compadres conhecidos" e “caboclos recém-chegados do interior” (HATOUM, 1999, p. 45) (mas não são as palafitas uma paisagem mais oriental do que brasileira?).

A cultura indígena faz-se sobretudo sentir quando pessoas dessa origem se relacionam com a família de imigrantes libaneses. É o caso do curandeiro Lobato Naturidade, o índio que ninguém sabe onde vive, que fala nhegatu sem embaraço e que é "mestre na cura de dores reumáticas, inchações, gripes, cólicas e um leque de doenças benignas” (HATOUM, 1999, p. 123). Ou Anastácia Socorro, a índia empregada da família, que maravilhava Emilie com a "descrição da trepadeira, das folhas malhadas de um tajá que reproduz a fortuna de um homem, das receitas de curandeiros" e as suas histórias com termos indígenas de um tempo e lugar remotos (HATOUM, 1999, p. 119). Ou ainda os “curumins e mendigos" que, no dia das oferendas, ofereciam a Emilie

[...] objetos, animais e plantas originários dos quatro cantos da Amazônia: pássaros e répteis vivos e empalhados, o precioso rouxinol do Rio Negro, mudas de trepadeiras, samambaias e palmeirais, peixinhos fosforescentes, piranhas embalsamadas, e até mesmo a réplica fiel de um remo sagrado que conta a história de uma tribo indígena (HATOUM, 1999, p. 132).

Porém, de uma forma geral esta saga procura evitar o exterior e assim evitar também a paisagem exótica - mesmo que esta até pudesse trazer para o livro, não a Amazónia, mas uma paisagem que associamos ao Oriente, se for verdade, como afirmou Gilberto Freyre (1963, p. 450), que o Brasil tem mais parentesco ecológico com o Oriente do que com o Ocidente, preso à sua "mística de pureza etnocêntrica” e à sua “intolerância sistemática do exótico”, e que

[...] ao findar do século XVIII e ao principiar do século XIX, em nenhuma outra área americana [...], o cuscus, 0 alfeolo, o alfenim, 0 arroz-doce com canela, 0 cravo das Molucas, a canela de Ceilão, a pimenta de Cochim, [...], os perfumes 
do Oriente, haviam se aclimado com o mesmo à-vontade que no Brasil e formado com valores indígenas, europeus e de outras procedências o mesmo conjunto simbiótico de natureza.

De qualquer forma, para bloquear a entrada da cultura indígena no Relato e se desviar do regionalismo, Hatoum tomou como cenário principal do declínio desta família de comerciantes libaneses dois espaços confinados, sobre os quais falaremos de seguida.

\section{OS ESPAÇOS FECHADOS E PRIVADOS EM RELATO DE UM CERTO ORIENTE}

Como se disse, a ação decorre sobretudo em dois espaços fechados, a Parisiense, com os seus quartos e os seus cubículos, e o sobrado, com as suas salas, quartos e corredores. Na sala de jantar do sobrado, a família vive os raros momentos de paz do dia a dia, quando deixa as divergências de lado para comentar os acontecimentos da cidade. No quarto, Samara Délia fecha-se durante cinco meses, quando já não pode negar a gravidez. Aí fica fechada com a filha Soraya Ângela até esta ter um ano, e mesmo depois disso, continua a viver dentro dos limites da casa, de lá saindo apenas para saídas esporádicas com o tio Hakim. É a poucos passos do sobrado que Soraya Ângela acaba por morrer atropelada. Anos mais tarde, Samara Délia decide mudar-se para um quarto... na Parisiense. E, na Parisiense, o pai conta a Dorner a história da sua chegada ao Brasil e do seu noivado com Emilie. Ao sobrado acorrem convivas e vizinhos para festas e banquetes, lavadeiras que trabalham a troco de comida, os filhos de Anastácia a quem a matriarca Emilie distribuía alimentos, e mendigos no dia das oferendas. No sobrado, morre Emilie. A degradação desta casa serve de face visível do declínio da família:

A casa está fechada e deserta, o limo logo cobrirá a ardósia do pátio, um dia as trepadeiras vão tapar as venezianas, os gradis, as gelosias e todas as frestas por onde o olhar contemplou o percurso solar e percebeu a invasão da noite, precipitada e densa (HATOUM, 1999, p. 204).

A presença do sobrado, casa enorme e rosada, impõe-se de tal modo no romance que a tradutora alemã chegou a pedir a Milton Hatoum que o dese- 
nhasse cada detalhe, algo que este diz ter feito com um prazer imenso (HATOUM, 2011).

\section{O DRAMA BURGUÊS DE IBSEN E RELATO DE UM CERTO ORIENTE}

O drama burguês é a peça de teatro que reflete a ascensão da burguesia europeia e representa o culminar de um progressivo fecho do palco da ação teatral desde o espaço aberto e público da tragédia grega. Num drama burguês, o cenário resume-se às três paredes de um salão de uma casa burguesa. Que ainda hoje se representem dramas oitocentistas, não obstante a produção dramatúrgica ter seguido no sentido da destruição do salão burguês e do afastamento da peça bem-feita, deve-se, em boa parte, à qualidade das peças escritas por Henrik Ibsen (1828-1906) depois dos cinquenta anos. É quando entra na fase mais interessante da sua carreira de dramaturgo: nos vinte anos que começam com Os pilares da sociedade (1877) e que terminam em Quando nós, os mortos (1899), Ibsen escreve obras-primas como John Gabriel Borkman (1899), Casa de bonecas (1879), Espectros (1881), O pato selvagem (1884), A casa de Rosmer (1886), A dama do mar (1888) e Hedda Gabler (1891). Ora, parece razoável sustentar que, quando concebeu a sua "epopeia burguesa". Hatoum foi influenciado pela obra de Ibsen, sobretudo pelas peças que produziu entre 1877 e 1891.

Ao centrar a ação no espaço privado da família burguesa, Relato evoca o naturalismo e o cenário de uma peça de um drama burguês. Há, de facto, qualquer coisa de profundamente ibseniano na vida familiar e nos espaços interiores descritos em Relato, com os seus móveis, espelhos, lustres venezianos, relógios de parede, nichos, prateleiras, cristaleiras, vitrines, cadeiras art déco e vitrolas, recantos e armários. Hatoum aliás cresceu e frequentou as casas burguesas de Manaus, algumas até mais europeias, como a do cônsul francês. Não obstante a ausência das salamandras que aquecem os salões de Ibsen, o ambiente da Parisiense e do sobrado é semelhante a este da sala de estar de Hedda Gabler:

Uma sala de estar espaçosa, bem mobilada e com muito bom gosto, decorada em paredes escuras. Na parede do fundo há uma passagem ampla com os reposteiros abertos. Essa passagem dá acesso a uma sala mais pequena, no mesmo estilo da sala de estar. Na parede do lado direito da sala da frente, uma 
porta conduz ao hall. Na parede oposta, à esquerda, uma porta de vidro, também com os reposteiros abertos. Pelas vidraças vê-se parte da varanda e árvores de cores outonais. Na parte dianteira da sala, uma mesa oval coberta por uma toalha, com cadeiras à volta. Junto à parede da direita vê-se uma salamandra grande e escura, revestida a azulejos, uma poltrona de encosto alto, um banco almofadado e dois tamboretes. No canto à direita, um sofá de canto e uma mesinha redonda. Na parte anterior, à esquerda, um pouco afastado da parede, um sofá. Diante da porta de vidro há um piano forte. De ambos os lados da porta ao fundo, prateleiras com peças decorativas de terracota e majólica. Contra a parede do fundo da saleta interior vê-se um sofá, uma mesa e duas cadeiras. Por cima do sofá, o retrato a óleo de um senhor de idade, elegante, em uniforme de general. Por cima da mesa, um candeeiro de teto de vidro fosco. Na sala de estar há vários ramos de flores sobre as mesas. 0 soalho de ambas as divisões está coberto com tapetes espessos. Iluminação matinal. 0 sol brilha através da porta de vidro (IBSEN, 2008a, p. 13).

E tal como num drama de Ibsen, também no romance de Hatoum, os “sofás, mesinhas, veludos, velas, degraus” são a "face visível de uma mentira que [ameaça] rebentar, a fachada de uma vitória incerta, a cola-tudo de uma insegurança, a aparência de um sucesso económico cuja derrocada se temia" (SILVA MELO, 2019, p. 252). Na vida de Manaus, realidade que Relato aborda, a mentira - isto é, a injustiça social - decorre de um modelo de sociedade patriarcal (e feudal) herdado do tempo da escravatura, cuja abolição definitiva teve lugar em 1888. O romance de Hatoum abarca um período de tempo amplo, mas a ação coberta pelos relatos coligidos pela narradora terá lugar entre 1910 e 1950. Nessa época a sociedade de Manaus replicava ainda o modelo de sociedade patriarcal e consequentemente os modos de exploração dos negros e indígenas na medida em que os senhores da casa-grande (rural) passaram para os sobrados (urbanos). Ora, a família libanesa que protagoniza o Relato, sendo o que se pode chamar de um caso de integração bem-sucedida, conforma-se e adapta-se a um sistema assente na desigualdade social, em que a regra é a exploração da pobreza dos indígenas pelas famílias abastadas, em que as lavadeiras trabalham a troco de comida e são submetidas a abusos pelos filhos dos patrões.

Mas a derrocada da família é intuída pelo leitor mesmo antes de esta ser inteiramente revelada, porque, tal como acontece no drama burguês, "todos, espectadores e personagens, sabiam que aquela riqueza de interiores estava assente na fugidia areia da injustiça social e da apropriação individual dos bens que até ameaçavam vir a ser coletivos” (SILVA MELO, 2019, p. 252). 
Como um espectador do drama burguês, que pode ser concebido como o voyeur que observa pelo buraco da fechadura (ALONGE, 1996, p. 11), o leitor do Relato e as personagens que criticam a conduta da família pressentem que aquele estado de coisas não pode subsistir. Dorner, observador imparcial, sabe que "aqui reina uma forma estranha de escravidão [...]. A humilhação e a ameaça são o açoite; a comida e a integração ilusória à família do senhor são as correntes e golilhas", e Hakim, o filho que não é "vítima” nem “agressor", deixa a família e Manaus "por não suportar a convivência estúpida com os serviçais” (HATOUM, 1999, p. 115).

No drama burguês, o "segredo, que os gregos fizeram derrubar, votando na praça pública, vai estar ao fundo da escada, na arca, na cave, atrás das portas” (SILVA MELO, 2019, p. 253). No Relato o segredo está em divisões invioláveis, em esconderijos, dentro de um cofre inglês, no fundo de baú que esconde o passado de Emilie num convento no Monte Líbano e a sua ameaça de suicídio. Mas, se "a peça de teatro, nos seus conturbados quatro atos, revelava essa mentira - revelação que podia ser letal, como para a pequena Hedvig de O Pato Selvagem de Ibsen” (SILVA MELO, 2019, p. 252), no Relato um segredo só fica vulnerável com uma mudança de casa: "mudar de casa traz revelações, deixa mistérios, e na passagem de um espaço a outro, algo se desvenda e até mesmo o conteúdo de um pergaminho secreto pode tornar-se público" (HATOUM, 1999, p. 68). O desenlace não é a revelação do segredo. As personagens espiam através da veneziana, das frestas dos janelões, vigiam movimentos através da parede, como em A casa de Rosmer, em que Rebekka escuta a conversa entre Rosmer e Mortensgaard. Mas essa "auscultação discreta" e "persistente", típica do drama burguês (ALONGE, 1995, p. 36), não tem, no Relato, função idêntica, isto é, não prepara o momento da revelação. No Relato um segredo pode continuar a ser segredo porque serve apenas de sintoma da desagregação familiar que terá lugar no final. Não ficaremos a saber por que se suicidou Emir, o que aconteceu na sua passagem por Marselha, quem é o pai de Soraya Ângela, nem para onde ou por que razão partiu Samara Délia.

A crueldade própria do "salão ibseniano", autêntico ringue onde as personagens aplicam golpes proibidos e se dizem coisas tremendas e cruéis (ALONGE, 1983, p. 8), não é tão direta no Relato (exceto quando provém dos dois irmãos gémeos). A crueldade da matriarca Emilie é passiva, está na sua indiferença perante os atos de crueldade dos filhos para com Samara Délia, está na dispensa de uma empregada "negra órfã", "tão faminta e triste que havia esquecido o seu nome e sobrenome e só se comunicava através de gestos 
e suspiros", apenas porque o papagaio embirrava com ela (HATOUM, 1999, p. 34), está ainda no temor dos convivas de não voltarem a ser convidados para as festas do sobrado. E está na indignidade com que é tratada a índia Anastácia Socorro, empregada da família que só é poupada ao abuso dos filhos inomináveis porque é feia e que é afastada do lugar que por breves momentos teve sentada à mesa da família porque aqueles não a conseguem tolerar.

$\mathrm{O}$ esquema de ofertas, ajudas, esmolas e comidas que alimenta os mais pobres de Manaus é mantido por Emilie sob uma aparência de generosidade, mas esconde formas de submissão e de dependência apenas destinadas a manter o seu estatuto na sociedade. São modos de afirmação social. Já foi proposto que a aparente abertura daquela casa libanesa e a generosidade de Emilie se aproximam de uma ideia de cordialidade brasileira desenvolvida por Sérgio Buarque de Holanda (CEZAR, 2014, p. 12). Holanda (1948, p. 101) sustenta que a "lhaneza no trato, a hospitalidade, a generosidade" são "um aspecto bem definido do carácter nacional". Mas a cordialidade de Emilie é uma cordialidade perversa que, tal como a civilidade no argumento de Holanda (1948, p. 101), tem "qualquer coisa de coercitivo", exprimindo-se "em mandamentos e em sentenças" (CÉZAR, 2014, p. 53). Aqui reside um dos aspetos em que a matriarca se aproxima das grandes personagens femininas de Ibsen, como Hedda, de Hedda Gabler, ou Nora, de Casa de bonecas.

Hedda também aparenta civilidade quando recebe em sua casa a senhora Elvset, mas essa civilidade é inteiramente coerciva. De facto, o texto de Hedda Gabler é rico em sequências em que a protagonista "obriga a senhora Elvset a sentar-se", ou "empurra a senhora Elvsted, quase com violência, em direcção à porta” (ALONGE, 1983, p. 66). No salão de Hedda Gabler, “sentar-se e falar não é mais um convite, mas uma ordem, uma coação. O salão torna-se uma câmara de tortura" (ALONGE, 1983, p. 66).

E Nora, que recebe a antiga amiga de escola, a Senhora Linde, "viúva, sem dinheiro, sem filhos, sem trabalho, precocemente envelhecida", com aparente afabilidade, lança-se afinal numa demonstração de insensibilidade e sadismo (ALONGE, 1983, p. 67). Nora passa o tempo a contrapor a infelicidade da Senhora Linde à sua própria felicidade: “Ah, pobre Kristine. Deves ter sofrido muito. Ele não te deixou nada? [...] E nem um filho? [...] Assim, sozinha, deve ser tão pesado para ti. Eu tenho três filhos deliciosos. Ah, tu não podes ver nenhum agora porque eles saíram com a criada" (ALONGE, 1983, p. 67-68; IBSEN, 2008b, p. 222). 
Não é só Emilie que encontra paralelo nas personagens de Ibsen. Tal como Erhart Borkman, personagem da peça John Gabriel Borkman, o jovem Hakim foge ao despotismo matriarcal abandonando a casa de família (ALONGE, 1983, p. 167), ainda que com motivações diferentes das de Borkman: Hakim não suporta a conivência de Emilie com os filhos inomináveis, Erhart apenas quer viver uma paixão com Fanny. Mas num e noutro (Relato de um certo Oriente e John Gabriel Borkman)

[...] nenhum [dos] velhos consegue impedir a liberdade dos mais novos. Ou, usando-os, parar o tempo para remediar a sua dor e dar sentido aos seus intermináveis dias [...]. Nenhum dos mais novos ocupará o lugar que lhe estava destinado na longa espera que garantiu a segurança dos mais velhos (SILVA MELO, 2019, p. 147-148).

\section{FLAUBERT E MACHADO DE ASSIS}

Flaubert é outro autor cuja obra estabelece relações com o romance de Hatoum, segundo o que parece ser um "plágio consciente" semelhante ao que, no ensaio "Laços de parentesco: ficção e antropologia”, Hatoum $(2005)^{3}$ conta ter feito para criar Domingas, a empregada do romance Dois irmãos. No ensaio, Hatoum (2005) diz ter extraído Domingas da servente Félicité do conto “Um coração simples”, de Flaubert - conto, aliás, já traduzido por Hatoum. A figura da servente, que Hatoum (2005, p. 86) reencontra "em Dona Plácida (a pobre costureira de Memórias Póstumas de Brás Cubas)", é "quase sempre alguém que trabalha sem descanso" e pertence "à imensa família de figuras femininas exploradas e humilhadas". Hatoum identifica expressamente a personagem Félicité de Flaubert como inspiração para criar Domingas, mas "é preciso inserir outra personagem nesse grupo de mulheres pobres - a empregada de Relato de um certo Oriente, Anastácia Socorro" (CÉZAR, 2014, p. 48). Como Félicité, Anástácia é um exemplo de "abnegação e responsabilidade" (HATOUM, 1999, p. 56), de contenção e decoro. Proibida como as outras empregadas da casa de comer frutas ou guloseimas, Anastácia transborda de gratidão quando, uma vez apanhada por Emilie a engolir uma tâmara com o caroço, Hakim mente à mãe dizendo que foi ele que ofereceu. Assim como

3 Recuperando uma expressão de Sérgio Buarque de Holanda "num ensaio erudito d'O Espírito e a Letra" (HATOUM, 2005, p. 87). 
Félicité fica reconhecida "como se de um obséquio se tratara", quando, num momento único de fraqueza, a patroa lhe dá um abraço (FLAUBERT, 2003, p. 43). É preciso pouco para contentar estas duas mulheres. A frieza de Mme. Aubier - quando, sobre Félicité, diz “como você é burra!” (FLAUBERT, 2003, p. 49) - é a mesma frieza de Emilie, que se queixa de que Anastácia "come como uma anta" (HATOUM, 1999, p. 112). E quando todos morrem ou abandonam a casa, Anastácia e Félicité persistem.

A enumeração e acumulação de objetos, recurso técnico que Hatoum utiliza ao longo do romance, é outro traço estilístico provindo do realismo de Flaubert. Senão veja-se a descrição do quarto de Félicité e compare-se com o elenco de objetos espalhados pela Parisiense:

Pelas paredes viam-se: terços, medalhas, várias Virgens Marias, uma taça de água benta feita de um coco; sobre a cómoda, como um altar, a caixa de conchinhas que the tinha dado o Vítor, e ainda um regador e uma bola, cadernos de escrever, a geografia ilustrada, um par de botinas; e no prego do espelho, pendurado pelas fitas, o chapeuzinho de peluche! (FLAUBERT, 2003, p. 53).

[...] cadinhos de porcelana, almofadas bordadas com arabescos, pequenos recipientes de cristal contendo cânfora e benjoim, alcovas, lustres formados de esferas leitosas de vidro, leques da Espanha, tecidos e uma coleç̧ão de frascos de perfume que do almíscar ao âmbar formava uma caravana de odores que eu aspirava enquanto repetia a palavra correcta para nomeá-los (HATOUM, 1999, p. 66).

Já a breve aparição do papagaio Laure no Relato parece apenas um aceno a Flaubert. O papagaio de Emilie, "dotado de forte sotaque do Midi" e capaz de pronunciar frases como "Soyez le bien venu" ou "je vais a Marseille, pas toi?” (HATOUM, 1999, p. 33, 35), é uma homenagem discreta a Loulou, papagaio de "Un coeur simple", que repete "Charmant garçon! Serviteur, monsieur! Je vous salue, Marie!” ou, imitando Mme. Aubain, "Félicité! La porte! La porte!" (FLAUBERT, 1981, p. 821-822).

Tecidas estas considerações a propósito da construção do romance de Hatoum, seria tentador avançar para a conclusão de que o processo de trabalho subjacente é, em certa medida, semelhante àquele que adotaram os escritores românticos regionalistas, ao convocarem modelos de uma literatura europeia para criar os seus modelos brasileiros. No entanto, em Relato não há uma adaptação das raízes ao comportamento das personagens. 
Contudo, parece-nos que, por exemplo, os irmãos inomináveis encontram o seu modelo na literatura brasileira oitocentista. Essas duas personagens parecem evocar um tempo em que a escravatura determinava o esquema de relações sociais. Gilberto Freyre (1983, p. 361, 354) atribuiu a este "sistema económico" que dividiu "a sociedade em senhores e escravos" o que considerou "a exagerada tendência para o sadismo característica do brasileiro, nascido e criado em casa-grande" e que encontrou no "brasileiro de classe mais elevada", "mesmo que "nascido e criado depois de oficialmente abolida a escravidão", que sente um "mórbido deleite em ser mau com os inferiores e com os animais”. Freyre (1983, p. 354) considerou-o "aparentado do menino Braz Cubas na malvadez e no gosto de judiar com os negros". Desde os cinco anos que o menino Braz Cubas, personagem do romance Memórias póstumas de Braz Cubas, de Machado de Assis, "merecera [...] a alcunha de "menino diabo", tendo sido verdadeiramente "dos mais malignos do seu tempo" (1914, p. 33). Por exemplo,

[...] quebrei a cabeça de uma escrava, porque me negara uma colher do doce de coco que estava fazendo, e, não contente com o malefício, deitei um punhado de cinza ao tacho, e, não satisfeito da travessura, fui dizer à minha mãe que a escrava é que estragara o doce "por pirraça" (ASSIS, 1914, p. 33-34).

Para além disso, fazia de Prudêncio, "um moleque da casa", o "cavalo de todos os dias”, a quem fustigava, dava mil voltas a um e outro lado, e ele obedecia - algumas vezes gemendo, - mas obedecia sem dizer palavra, ou, quando muito, um - "ai, nhônhô!", ao que o menino diabo retorquia, "cala a boca, besta!" (ASSIS, 1943, p. 34).

É notório o sadismo destes irmãos, que “abusavam como podiam das empregadas, que às vezes entravam no dia e saíam no outro, marcadas pela violência física e moral", esbofeteavam e agrediam Anastácia Socorro porque não tinha "paciência para preparar o café da manhã cada vez que alguém acordava, já no meio dia”, que engravidavam empregadas e as enxotavam com violência quando estas procuravam apoio no sobrado (HATOUM, 1999, p. 112-113). Em Relato, não há descrições da infância destes irmãos inomináveis. E se as houvesse não seriam as suas atitudes semelhantes às descritas por Braz Cubas? 


\section{Nineteenth-century literature and Milton Hatoum's Tale of a certain Orient}

\section{Abstract}

Taking as a starting point the desire expressed by Milton Hatoum in the book Tale of a certain Orient to avoid the regionalist tradition associated with the Amazonian novel, this essay attempts to establish intertextual relations between Hatoum's novel and several canonic texts from the nineteenth-century literature, marked by naturalism and realism. Specifically, relations are established with the bourgeois drama and with different characters from Henrik Ibsen's plays. The article also explores the proximity between Tale of a certain Orient and some references from Flaubert and Machado de Assis' work.

\section{Keywords}

Hatoum. Bourgeois drama. Flaubert.

\section{REFERÊNCIAS}

ALONGE, R. Epopea borghese nel teatro di Ibsen. Napoli: Guida Editori, 1983.

ALONGE, R. L'opera e la fortuna scenica. Firenze: Editrice Le Lettere, 1995.

ALONGE, R. Scene perturbanti e rimosse: interno ed esterno sulla scena teatrale. Roma: La Nuova Italia Scientifica, 1996.

ASSIS, M. de. Memorias posthumas de Braz Cubas. Rio de Janeiro: Livraria Garnier, 1914.

BORGES, J. D. Entrevista com Milton Hatoum. Digestivo Cultural, 2005. Disponível $\mathrm{em}$ : https://www.digestivocultural.com/entrevistas/entrevista.asp?codigo $=1 \&$ titulo= Milton_Hatoum. Acesso em: 14 fev. 2020.

CANDIDO, A. Formação da literatura brasileira: momentos decisivos. São Paulo: Livraria Martins, 1964. 2 v.

CEZAR, L A. de S. E o futuro se dissolvia no mormaço amazônico: paralisia econômica e solidão cultural na Manaus de Relato de um certo Oriente. 2014. Dissertação (Mestrado em Literatura Brasileira) - Universidade Federal do Rio Grande do Sul, Porto Alegre, 2014. Disponível em: https://lume.ufrgs.br/handle/10183/103885. Acesso em: 14 fev. 2020. 
FLAUBERT, G. Un coeur simple. In: FLAUBERT, G. Madame Bovary, L'éducation sentimentale, Bouvard et Pécuchet, Le dictionnaire des idées reçues, Trois contes. Paris: Éditions Robért Laffont, 1981.

FLAUBERT, G. Um coração simples. Tradução Telma Costa. Lisboa: Editorial Teorema, 2003.

FREYRE, G. Sobrados e mucambos: decadência do patriarcado rural e desenvolvimento do urbano. Lisboa: Livros do Brasil, 1963. t. 2.

FREYRE, G. Casa-grande \& senzala: formação da família brasileira sob o regime da economia patriarcal. Lisboa: Livros do Brasil, 1983.

HATOUM, M. Escrever à margem da história. In: SEMINÁRIO DE ESCRITORES BRASILEIROS E ALEMÃES, 1993, São Paulo. São Paulo: Instituto Goethe, 1993. Disponível em: http://www4.pucsp.br/revistafronteiraz/numeros_anteriores/n2/download/Escrever\%20_Margem_Historia.pdf . Acesso em: 14 fev. 2020.

HATOUM, M. Relato de um certo Oriente. Lisboa: Cotovia, 1999.

HATOUM, M. Laços de parentesco: ficção e antropologia. Raízes da Amazônia, v. 1, n. 1, p. 81-87, 2005. Disponível em: https://docplayer.com.br/18915158-Lacos-de-parentesco-ficcao-e-antropologia.html. Acesso em: 17 fev. 2020.

HATOUM, M. Um escritor na biblioteca. Transcrição de excertos da conversa de Hatoum com Flávio Stein. Jornal da Biblioteca Pública do Paraná, 2011. Disponível em: http://www.candido.bpp.pr.gov.br/modules/conteudo/conteudo.php?conteudo=142. Acesso em: 17 fev. 2020.

HOLANDA, S. B. de. Raízes do Brasil. São Paulo: Livraria José Olympo, 1948.

IBSEN, H. Peças escolhidas 2. Lisboa: Edições Cotovia, 2008a.

IBSEN, H. Peças escolhidas 3. Lisboa: Edições Cotovia, 2008b.

PELLEGRINI, T. Milton Hatoum e o regionalismo revisitado. Luso-Brazilian Review, Madison, v. 41, n. 1, p. 121-138, 2004. doi: 10.1353/lbr.2004.0020.

SILVA MELO, J. A mesa está posta. Lisboa: Livros Cotovia, 2019.

TEIXEIRO, A. M. Relato de um cierto Oriente (La vision de la identidad y de la alteridad respecto a los referentes árabes en la literatura brasileña contemporánea). 1616: Anuario de Literatura Comparada, Salamanca, v. 3, p. 67-89, 2013. Disponível em: https://revistas.usal.es/index.php/1616_Anuario_Literatura_Comp/article/view/12440. Acesso em: 17 fev. 2020.

TOLEDO, M. P. M. e F. de. Milton Hatoum: itinerário para um certo relato. São Paulo: Ateliê, 2006. 